\title{
Smoking behaviour, knowledge and attitudes among Family Medicine physicians and nurses in Bosnia and Herzegovina Geoffrey Hodgetts ${ }^{1,2}$, Teresa Broers*2 and Marshall Godwin ${ }^{1,2}$
} Address: ${ }^{1}$ Department of Family Medicine, Queen's University, 220 Bagot Street, Kingston, Canada and ${ }^{2}$ Queen's University Family Medicine
Development Program in the Balkans Region, Queen's University, 220 Bagot Street, Kingston, Canada

Email: Geoffrey Hodgetts - hodgetts@post.queensu.ca; Teresa Broers* - broerst@post.queensu.ca; Marshall Godwin - godwinm@post.queensu.ca

* Corresponding author

Published: II June 2004

BMC Family Practice 2004, 5:12 doi:10.1186/147|-2296-5-12
Received: 05 February 2004

Accepted: II June 2004

This article is available from: http://www.biomedcentral.com/I47/-2296/5/12

(C) 2004 Hodgetts et al; licensee BioMed Central Ltd. This is an Open Access article: verbatim copying and redistribution of this article are permitted in all media for any purpose, provided this notice is preserved along with the article's original URL.

\begin{abstract}
Background: Smoking rates among the general population in Bosnia and Herzegovina are extremely high, and national campaigns to lower smoking rates have not yet begun. As part of future activities of the Queen's University Family Medicine Development Program in the Balkans Region, technical assistance may be provided to Bosnia and Herzegovina to develop of national tobacco control strategies. This assistance may focus on training doctors and nurses on smoking cessation strategies with a view to helping their patients to stop smoking. Given this important role that health professionals have, data is needed on smoking rates as well as on smoking behaviour among doctors and nurses in Bosnia and Herzegovina. This study therefore seeks to determine the smoking rates and behaviour of family medicine physicians and nurses in Bosnia and Herzegovina and to determine how well prepared they feel with respect to counselling their patients on smoking cessation strategies.
\end{abstract}

Methods: The WHO Global Health Professional Survey, a self-administered questionnaire, was distributed to physicians and nurses in 19 Family Medicine Teaching Centres in Bosnia and Herzegovina in June 2002. Smoking rates and behaviour, as well as information on knowledge and attitudes regarding smoking were determined for both physicians and nurses.

Results: Of the 273 physicians and nurses currently working in Family Medicine Teaching Centres, 209 (77\%) completed the questionnaire. Approximately $45 \%$ of those surveyed currently smoke, where $51 \%$ of nurses smoked, compared to $40 \%$ of physicians. With respect to knowledge and attitudes, all respondents agreed that smoking is harmful to one's health. However, "ever" smokers, compared to "never" smokers, were less likely to agree that health professionals who smoke were less likely to advise patients to quit smoking than non-smoking health professionals. Less than half of physicians and nurses had received formal training in smoking cessations strategies, but about two thirds of health professionals felt very or somewhat prepared to counsel their patients on how to quit smoking.

Conclusions: Our study indicates that almost half of Family Medicine health professionals in Bosnia and Herzegovina are smokers. This indicates a severe public health problem throughout the country. Steps need to be taken at a national level to address the fight against tobacco. 


\section{Background}

The 1950s ground-breaking studies by Doll and Hill [1-3] demonstrating the effect of smoking on morbidity and mortality have been replicated time and time again, whereby epidemiologic studies are no longer needed to show that smoking is strongly related to adverse health. Rather, efforts in many parts of the world are now being directed towards the fight against tobacco, which have been successful throughout several countries. One example where smoking cessation programs and public health campaigns have been instrumental in decreasing overall smoking rates countrywide is Canada. In 1965, between $42 \%$ and $45 \%$ of Canadians smoked, except in the province of Quebec, where the proportion was 51\% [4]. Today, the overall rate is down to just $21.5 \%$ nationwide [5].

Anti-smoking campaigns have not yet been introduced in Bosnia and Herzegovina (BiH) to any significant degree, where smoking rates shortly after the Balkan conflict were $48 \%$ for adults [6]. Another WHO study in BiH estimated that $55 \%$ of male and $50 \%$ of female physicians smoked in 1996 [6].

Given the important role that doctors and nurses have in educating their patients about good health practices, the smoking figure for physicians is disturbing. Doctors and nurses are often seen as symbols of good health practice [7]. Moreover, they can, and should, play a crucial role in influencing the smoking habits of their patients. In particular, family physicians have a key role in counselling their patients on smoking cessation strategies; for example, they are the first point of medical contact for most patients, they have an ongoing relationship with their patients, and they come into contact with a large number of smokers, especially in countries such as Bosnia and Herzegovina where smoking rates are high.

With funding from the Canadian International Development Agency, the Department of Family Medicine at Queen's University has been working in Bosnia and Herzegovina since 1995 to establish an effective family medicine educational infrastructure. Doctors and nurses are being trained to work within a family medicine framework, providing comprehensive and continuous care to their patients, as well as educating patients about health and good health practices. As part of the health education aspect of their work, family medicine physicians and nurses are encouraged to promote a smoke-free lifestyle to their patients.

A plan for future activities of the Queen's University Family Medicine Development Program in the Balkans Region includes technical assistance to several Balkan countries in the development of national tobacco strategies. This assistance would focus on training doctors and nurses on smoking cessation strategies with a view to helping their patients to stop smoking. For these training programs to be effective, baseline data is needed on smoking behaviour, as well as on the knowledge and attitudes about smoking among doctors and nurses in Bosnia and Herzegovina.

The main objectives of this study are to determine smoking behaviour and rates among Family Medicine (FM) doctors and nurses in Bosnia and Herzegovina; assess the knowledge and attitudes of the FM doctors and nurses regarding adverse health risks of smoking; and determine how well prepared the health professionals currently feel with respect to counselling their patients on smoking cessation strategies.

\section{Methods}

The study population included all Family Medicine (FM) physicians and nurses working in the Family Medicine Teaching Centres of Sarajevo, Tuzla, Mostar, Zenica, Doboj, and Banja Luka in June 2002 who have been or are being trained as part of the Queen's University Family Medicine Development Program in the Balkans Region. The Family Medicine training included information on the adverse effects of smoking on health and short courses on smoking cessation.

This descriptive study used the Global Health Professional Survey (see Additional File 1), a self-administered questionnaire developed by the Tobacco Free Initiative, a project of the World Health Organization, in collaboration with the Centers for Disease Control and a number of additional partners [8]. This standardized survey instrument aims to monitor and document the prevalence of tobacco use among health professionals and assess their knowledge, attitudes and behaviours towards tobacco and tobacco control policies. The questionnaire was slightly shortened to make it more amenable for use by the FM physicians and nurses in Bosnia and Herzegovina.

The first section of the questionnaire is made up of basic demographic questions, followed by a section on personal smoking behaviour. These include questions on how many cigarettes one smokes, when a smoker started or quit smoking, and their feelings towards smoking in terms of "stages of change" (Not ready to quit within the next 6 months; thinking about quitting within 6 months; ready to quit now). The next section consists of 22 questions (see Table 2) that assess knowledge of and attitudes towards the adverse affects of smoking, the role of health professionals regarding smoking cessation in their patients, and some policy issues of smoking. The final section evaluates the training they may have received in 
Table 2: Percentage agreement with knowledge and attitude statements between physicians and nurses and between ever and never smokers ( $n=105$ for physicians; $n=95$ for nurses).

\begin{tabular}{|c|c|c|c|c|c|}
\hline & \multirow[b]{2}{*}{ Question } & \multicolumn{2}{|c|}{ Physicians } & \multicolumn{2}{|c|}{ Nurses } \\
\hline & & Ever smoker & Never smoker & Ever smoker & Never smoker \\
\hline I & Smoking is harmful to your health. & 100.0 & 100.0 & 100.0 & 100.0 \\
\hline 2 & $\begin{array}{l}\text { Health professionals serve as role models for their patients and the } \\
\text { public. }\end{array}$ & 89.8 & 92.5 & 83.8 & 93.1 \\
\hline 3 & Health professionals should set a good example by not smoking. & 96.6 & 100.0 & 92.6 & 96.6 \\
\hline 4 & $\begin{array}{l}\text { Patient's chances of quitting smoking are increased if a health } \\
\text { professional advises him or her to quit. }\end{array}$ & 81.4 & 88.7 & 80.9 & 82.8 \\
\hline 5 & $\begin{array}{l}\text { Health professionals should routinely ask about their patients } \\
\text { smoking habits. }\end{array}$ & $100.0 \dagger$ & $100.0 \dagger$ & $86.8+$ & $89.7 \dagger$ \\
\hline 6 & $\begin{array}{l}\text { Heath professionals should routinely advise their smoking patients to } \\
\text { quit smoking. }\end{array}$ & $96.6+$ & $96.2 \dagger$ & $85.3+$ & $96.6 \dagger$ \\
\hline 7 & $\begin{array}{l}\text { Health professionals who smoke are less likely to advise people to } \\
\text { stop smoking. }\end{array}$ & $64.4 *$ & $84.9 *$ & $57.4 *$ & $82.8 *$ \\
\hline 8 & $\begin{array}{l}\text { Health professionals should get specific training on cessation } \\
\text { techniques. }\end{array}$ & 84.7 & 88.7 & 77.9 & 93.1 \\
\hline 9 & $\begin{array}{l}\text { Health professionals should speak to community groups about } \\
\text { smoking. }\end{array}$ & 89.8 & 94.3 & 88.2 & 89.7 \\
\hline 10 & Smoking in enclosed public places should be prohibited. & $96.6 \dagger$ & $100.0 \dagger$ & $77.9 * \dagger$ & $100.0 * \dagger$ \\
\hline 11 & Health warnings on cigarette packages should be in big print. & 86.4 & 90.6 & 79.4 & 86.2 \\
\hline 12 & Tobacco sales to children and adolescents should be banned. & $93.2 *$ & $100.0 *$ & 94.1 & 96.6 \\
\hline 13 & Sport sponsorships by tobacco industry should be banned. & 86.4 & 86.8 & 86.8 & 79.3 \\
\hline 14 & $\begin{array}{l}\text { There should be a complete ban on the advertising of tobacco } \\
\text { products. }\end{array}$ & $93.2 \dagger$ & $90.6+$ & $79.4 \dagger$ & $82.8+$ \\
\hline 15 & Hospitals and health care centres should be "smoke-free". & $96.6+$ & $100.0 \dagger$ & $86.8 * \dagger$ & $100.0 * \dagger$ \\
\hline 16 & The price of tobacco products should be increased sharply. & $78.0 * \dagger$ & $94.3 *+$ & $61.8 *+$ & $93.1 *+$ \\
\hline 17 & Neonatal death is associated with passive smoking. & 79.7 & $81.1^{\circ}$ & 64.7 & 79.3 \\
\hline 18 & $\begin{array}{l}\text { Maternal smoking during pregnancy increases the risk of Sudden } \\
\text { Infant Death Syndrome. }\end{array}$ & 93.2 & 86.8 & $75.0 *$ & $96.6 *$ \\
\hline 19 & $\begin{array}{l}\text { Passive smoking increases the risk of lung disease in non-smoking } \\
\text { adults. }\end{array}$ & $100.0 \dagger$ & $98.1 \dagger$ & $91.2 \dagger$ & $96.6 \dagger$ \\
\hline 20 & $\begin{array}{l}\text { Passive smoking increases the risk of heart disease in non-smoking } \\
\text { adults. }\end{array}$ & 88.1 & 90.6 & 88.2 & 93.1 \\
\hline 21 & $\begin{array}{l}\text { Paternal smoking increases the risk of lower respiratory tract } \\
\text { illnesses such as pneumonia in exposed children. }\end{array}$ & 94.9 & 88.7 & 94.1 & 100.0 \\
\hline 22 & $\begin{array}{l}\text { Health professionals should routinely advise patients who smoke to } \\
\text { avoid smoking around children. }\end{array}$ & 100.0 & 100.0 & 97.1 & 100.0 \\
\hline
\end{tabular}

* indicates $p$-value $<0.05$ between ever and never smokers $\dagger$ indicates $p$-value $<0.05$ between physicians and nurses

smoking cessation counselling, as well as their comfort level in counselling patients to stop smoking.

The WHO questionnaire and study information sheet were translated into Bosnian-Serbo-Croatian (see Additional File 2) then translated back into English by a second translator. Any differences in meaning or emphasis were identified and corrected. Thereafter, the questionnaire was pilot tested on four Bosnian health professionals to determine clarity of questions and length of time needed for questionnaire completion, which was found to be less than 15 minutes.

Data collection took place in June 2002. Questionnaires were distributed to all 19 Family Medicine Teaching Cen- tres (FMTCs) in Sarajevo, Tuzla, Zenica, Mostar, Doboj, and Banja Luka and were picked up one week later to allow sufficient time for all nurses and physicians to complete the questionnaire. A sealed marked box was left in each FMTC for confidential submission of the completed questionnaires. Denominator data were determined by asking the head physician at each clinic to complete a brief questionnaire regarding the total number of nurses and physicians working at the clinic. This questionnaire was dropped into the sealed box along with the smoking questionnaires.

All data were entered into Microsoft Access and analyzed using SPSS. Differences between groups were analyzed using Chi-square tests and relative risks. For the purpose 
Table I: Demographic data and smoking rates $(n=205)$.

\begin{tabular}{|c|c|c|c|c|c|}
\hline \multicolumn{2}{|c|}{ Characteristics } & Current Smokers & Ex Smokers & Never Smoked & Total \\
\hline \multicolumn{2}{|c|}{ All responders } & $92(44.9 \%)$ & $35(17.1 \%)$ & $78(38.0 \%)$ & $205(100.0 \%)$ \\
\hline \multirow[t]{2}{*}{ Sex } & Female & $86(46.0 \%)$ & $30(16.0 \%)$ & $71(38.0 \%)$ & $187(91.2 \%)$ \\
\hline & Male & $6(33.3 \%)$ & $5(27.8 \%)$ & $7(38.9 \%)$ & $18(8.8 \%)$ \\
\hline \multirow[t]{2}{*}{ Occupation } & Physician & $44(40.0 \%)$ & $15(13.6 \%)$ & $5 \mathrm{I}(46.4 \%)$ & $110(53.7 \%)$ \\
\hline & Nurse & $48(50.5 \%)$ & $20(21.1 \%)$ & $27(28.4 \%)$ & $95(46.3 \%)$ \\
\hline \multirow[t]{2}{*}{ Age } & $<=39$ & $59(48.8 \%)$ & $17(14.0 \%)$ & $45(37.2 \%)$ & $12 \mid(59.0 \%)$ \\
\hline & $40+$ & $33(39.3 \%)$ & $18(21.4 \%)$ & $33(39.3 \%)$ & $84(41.0 \%)$ \\
\hline
\end{tabular}

of some analysis, the respondents were divided into "ever" and "never" smokers, based on their current, past, or non-smoking history, and age range was determined by the median/mean age. This study received ethics approval from the Queen's University Human Research Ethics Board.

\section{Results}

There were 273 health professionals (153 physicians and 120 nurses) working in Family Medicine Teaching Centres at the time of data collection. Of those, 209 health professionals (112 physicians and 97 nurses) completed the questionnaire, for a $77 \%$ response rate overall $(73 \%$ and $81 \%$ respectively). Four questionnaires were removed due to excessive missing information, so a total of 205 questionnaires were used for all further analyses.

\section{Demographics and smoking rates}

Table 1 is a breakdown of the respondents by sex, age, and profession and also provides smoking rates for each. Overall, 92 (45\%) currently smoke, 35 (17\%) are exsmokers and $78(38 \%)$ never smoked. The group was overwhelmingly female (over 90\%), reflecting the demographics of primary care in $\mathrm{BiH}$, with a mean age of 37.7 years (standard deviation [SD]: 6.2 , range 22 to 55 years). Of the 187 women, $46 \%$ currently smoked, with $40 \%$ among physicians and 50\% among nurses (breakdown by sex not shown due to cells $<5$ for males).

\section{Smoking behaviours}

For those who currently smoke, the mean number of years that an individual has smoked is 14 years (SD: 6.3) for both men and women, and for physicians and nurses. Thirty-one percent of those who currently smoke began smoking in the past 10 years. The mean number of cigarettes smoked daily is 16 cigarettes (SD: 8.9) for both physicians and nurses. Men tend to smoke more than women - 21 cigarettes daily on average (SD: 10.1 , range 7 to 35 ) for men compared to 15 (SD: 8.7, range 1 to 61) for women, although this is not significant.
Ex-smokers had smoked on average 11.8 years (SD: 6.3) before quitting, and approximately $68 \%$ of ex-smokers had quit smoking in the past seven years. The mean number of years smoked was similar for physicians and nurses, from 12.1 years for physicians and 11.4 years for nurses (SD: 6.6, 6.3 resp.). There is a larger difference, however, between the number of years that men (17.3 years; SD: 5.8$)$ and women (11.0 years; SD: 6.1 ) smoked in the past, but again, these were not statistically significant.

\section{Stages of change}

Of the 92 people who currently smoke, 82 responded to questions about stages of change. Sixteen $(20 \%)$ said they were ready to quit now, $34(41 \%)$ said they were thinking about quitting within the next six months, and 32 (39\%) said they were not ready to quit within the next six months. Physicians were significantly more likely to be considering or ready to quit than nurses and those who had tried to quit smoking in the past were more likely to be considering quitting again.

In terms of amount of cigarettes smoked, there was a decreasing trend from 17,15 , and 12 cigarettes daily (SD: $6.7,4.6,11.9$, respectively) on average, representing those who are not ready to quit within six months, thinking about quitting within six months, and those ready to quit now, respectively, but this was not statistically different across the three categories. However, average daily cigarette consumption did differ significantly $(\mathrm{p}<0.05)$ for those who have tried to quit in the past (14 cigarettes; SD: 7.4) compared with those who have not tried to quit in the past (22 cigarettes; SD: 11.5).

\section{Attitudes and knowledge}

Table 2 presents the results of the percentage agreement with knowledge and attitude statements in the questionnaire compared by occupation and by ever/never smokers. All respondents agreed that smoking is harmful to health and, in general, all respondents had "appropriate" attitudes towards smoking. However, there were some significant differences between physicians and nurses and 
Table 3: Degree of "feeling prepared" among health professionals in smoking cessation counseling $(n=20 \mathrm{I})$

\begin{tabular}{llcc}
\hline Degree of preparedness & Physicians & Nurses & Total \\
\hline Very well prepared & $34(30.9 \%)$ & $39(42.9 \%)$ & $73(36.3 \%)$ \\
Somewhat prepared & $65(59.1 \%)$ & $42(46.2 \%)$ & $107(53.2 \%)$ \\
Not at all prepared & $11(10.0 \%)$ & $10(11.0 \%)$ & $21(10.4 \%)$ \\
\hline
\end{tabular}

between ever/never smokers regarding the advisory role that health professionals have.

More significant differences were seen in attitudes towards policy issues, where "ever" smokers were generally less likely to agree with statements that would change their current freedom to smoke. Most physicians and nurses agreed, however, that tobacco sales should be banned to children and youth.

With respect to adverse effects of passive smoking, most health professionals agreed that they should advise smoking patients to avoid smoking around children. However, only $64.7 \%$ of "ever" smoking nurses and approximately $80 \%$ of the remaining health professionals agreed that neonatal death is associated with passive smoking.

\section{Training in smoking cessation}

The physicians and nurses were also asked if they had ever received formal training on strategies for smoking cessation and whether they felt prepared to counsel patients on how to stop smoking. Fifty percent of nurses and $43 \%$ of doctors claimed they had received formal training. However, as Table 3 points out, only $36 \%$ of the health professionals felt very prepared to counsel patients while 53\% felt somewhat prepared.

\section{Discussion}

Smoking among physicians and nurses in $\mathrm{BiH}$ is extremely high, however, the smoking rates of $45 \%$ among all health professionals are slightly lower than comparable rates found in the literature. A WHO study after the Bosnian conflict found that $55 \%$ of male and $50 \%$ of female physicians smoked in 1996 [6]. Another survey of 620 health professionals in the Tuzla area in 1995 found an overall smoking prevalence of 53\%, with similar levels of smoking among males and females [9]. That particular study did find a difference in rates between physicians and nurses, however, with $47.9 \%$ for general practitioners, $42.5 \%$ for specialists and $58.3 \%$ for nurses [9]. It is possible, however, that rates were at their highest immediately following the Balkans conflict and have now begun to experience a decline. This is especially likely since our results showed that almost one third of the cur- rent smokers began smoking during or shortly following the conflict, possibly as a direct result of the conflict. Furthermore, the fact that almost two thirds of past smokers in this study have quit smoking in the seven years since the end of the conflict again suggest that rates were highest immediately after the war and are perhaps on the decline; this hypothesis requires further investigation.

It is to be expected that health professionals reflect the culture and behaviour in which they live, and so the rate of smoking among health professionals will vary in a similar manner as those adults in the general population. So, the rate of smoking among health professionals in Bosnia and Herzegovina is not surprising given that overall smoking rates were reported around $48 \%$ for adults [10]. The rates are particularly high, however, compared to other European countries. A study on Italian general practitioners determined that $28.3 \%$ smoked in 2000 [11], while Italy's National Statistical Institute found the rate of daily adult smokers to be around $25 \%$ in 2001 [10]. In the Netherlands, overall smoking prevalence was 33\% in adults in 2001 [10]; several years earlier, another study found that $25 \%$ of physicians and $44 \%$ of nurses were smokers [9]. In the United States, while nurses had a smoking prevalence of $18 \%$ in 1991, physicians had a low prevalence of 3.3\% [12]. So a rate of $40 \%$ among physicians and $51 \%$ for nurses in Bosnia and Herzegovina is considerable.

The decreasing trend of cigarettes smoked as the individual's willingness to quit increases is consistent with Prochaska and DiClemente's stages of change theory [13].

As for the knowledge and attitude questions, the differences in agreement with the statements related to the responsibilities of health care professionals and smoking policy could be expected between the "ever" and "never" smokers, as similar differences in attitudes between "ever" and "never" smokers were seen in another study done in the Netherlands [14]. These differences were less expected between physicians and nurses, however. Regarding knowledge of adverse effects of smoking, overall results were quite positive. Smoking cessation and the adverse health effects of smoking have been topics in both the Family Medicine specialization program as well as in the Family Medicine nursing program, both coordinated by 
the Queen's University project. No baseline data were taken before the training programs began, however, so it is not known whether this knowledge about smoking was acquired through the program or elsewhere. Results thus must be considered exploratory.

Counselling by health professionals on smoking cessation is crucial if their patients are going to quit smoking. The relatively high rates of health professionals having received formal training reflects the sampling frame of participants who are in a primary care specialization program. And indeed, almost 90\% felt very or somewhat well prepared to counsel their patients on smoking cessation. However, it may be possible that health professionals not actively counselling patients on smoking cessation may underestimate the difficulty of successfully supporting their patients through to smoking cessation [11]. More formal training about smoking cessation strategies through continuing education of health professionals in Bosnia and Herzegovina may be justified. This need for more training on smoking cessation strategies has been highlighted in another study on general practitioners in Italy [11].

This study on smoking rates, knowledge and attitudes of smoking among Family Medicine health professionals in Bosnia and Herzegovina is an exploratory one, given several limitations. One limitation of this study was our inability to obtain exact denominator data of the respondents. In the absence of an official staff list for each clinic, we selected the most reliable alternative for obtaining denominator data, described in the methods. Staffing of clinics in Bosnia and Herzegovina is quite standardized, where one physician and two nurses constitute a team, and each team shares one office space. So, a head physician in a clinic will be able to report with near certainty how many physicians and nurses work in a given clinic. Thus, we are satisfied that the denominator data is quite accurate.

Another concern is that the sampling frame, which comprises all Family Medicine physicians and nurses working in Bosnia and Herzegovina in June 2002, is not representative of all physicians and nurses in the country. Primary care services, including Family Medicine, are heavily weighted towards female health professionals. This is a pattern observed throughout the Balkans. However, Family Medicine is a new specialization in Bosnia and Herzegovina, and almost all the physicians and nurses in the program were general practitioners or specialists in other primary care fields, including General Medicine, Pediatrics, Obstetrics, etc. before joining this new Specialization. Therefore, with respect to smoking rates and behaviours, we believe that the study results are at least indicative of the rates and behaviours of the majority of primary care physicians and nurses in Bosnia and Herzegovina. However, given the fact that the physicians and nurses recently completed a lengthy training program, which included seminars on the adverse effects of smoking and smoking cessation strategies, the study results on the knowledge and attitudes of smoking will be overestimated with respect to other primary care physicians and nurses in the country. We do believe, however, that the results continue to suggest some interesting trends between ever/never smokers and between physicians and nurses.

\section{Conclusions}

This study indicates that almost half of all Family Medicine health professionals in Bosnia and Herzegovina are smokers. Given the important role physicians have in counselling their patients on smoking cessation techniques, these rates are disturbing and indicate a severe public health problem throughout the country. Steps need to be taken at a national level to address the fight against tobacco.

\section{Competing Interests}

None declared.

\section{Authors' contributions}

GH contributed to the conception and study design and critical revision of the manuscript. TB contributed to the study design, performed the data analysis and interpretation, and drafted the manuscript. MG participated in the conception and study design, data analysis and interpretation, and critical revision of the manuscript. All authors read and approved the final manuscript.

\section{Additional material}

\section{Additional File 1}

Global Health Professional Survey - English version. Microsoft Word. This file contains the Global Health Professional Survey developed by the World Health Organization and modified by the Queen's University Family Medicine Development Program in the Balkans Region. Formatted to be printed back to back in booklet form.

Click here for file

[http://www.biomedcentral.com/content/supplementary/14712296-5-12-S1.doc]

\section{Additional File 2}

Global Health Professional Survey - BiH version. Microsoft Word. This file contains the translated version in Serbo-Croat of the Global Health Professional Survey developed by the World Health Organization and modified by the Queen's University Family Medicine Development Program in the Balkans Region. Formatted to be printed back to back in booklet form.

Click here for file

[http://www.biomedcentral.com/content/supplementary/14712296-5-12-S2.doc] 


\section{Acknowledgements}

The authors would like to thank all the Family Medicine physicians and nurses who participated in this study and the local project staff in Sarajevo and Banja Luka for helping to coordinate the distribution and collection of questionnaires for this study.

\section{References}

I. Doll R, Hill AB: Smoking and carcinoma of the lung. Preliminary report. British Medical Journal 1950, 2:739-748.

2. Doll $R$, Hill $A B$ : A study of the aetiology of carcinoma of the lung. British Medical Journal 1952, 2: 127I-1286.

3. Doll $R$, Hill $A B$ : Lung cancer and other causes of death in relation to smoking: A second report on the mortality of British doctors. British Medical Journal 1956, 2:107I-108I.

4. Blanchette $C$ : Tobacco consumption - evolution and trends. PRB 98-8E Parliamentary Research Branch; 1998.

5. Statistics Canada: CANSIM II. Percentage of smokers in the population. Catalogue no.82-22 I-XIE Statistics Canada; 200 I.

6. Corrao MA, Guindon GE, Sharma N, Shokoohi DF: Tobacco Control Country Profiles. Atlanta, GA: American Cancer Society; 2000.

7. Mausner JS: Smoking in medical students. A survey of attitudes, information, and smoking habits. Arch Environ Health 1966, I3(I):5I-60.

8. World Health Organization: Noncommunicable diseases and mental health; Progress report 2000. Report \# MIPIOI IAPR.NMH $200 \mathrm{I}$.

9. World Health Organization: Tobacco or Health: A Global Status Report. Country Profiles by Region 1997.

10. Mackay J, Eriksen M: The Tobacco Atlas. Geneva: World Health Organization; 2002.

II. Pizzo AM, Chellini E, Grazzini G, Cardone A, Badellino F: Italian general practitioners and smoking cessation strategies. Tumori 2003, 89(3):250-254.

12. Nelson DE, Giovino GA, Emont SL, Brackbill R, Cameron LL, Peddicord J, Mowery PD: Trends in cigarette smoking among US physicians and nurses. JAMA 1994, 27 I(16): I273-I 275.

13. Prochaska JO, Velicer WF, Rossi JS, Goldstein MG, Marcus BH, Rakowski W, Fiore C, Harlow LL, Redding CA, Rosenbloom D, Rossi SR: Stages of Change and Decisional Balance for 12 Problem Behaviors. Health Psychology 1994, I 3( I):39-46.

14. Waalkens HJ, Cohen SJ, Adriaanse H, Knol K: Smoking habits in medical students and physicians in Groningen, The Netherlands. Eur Respir J 1992, 5(I):49-52.

\section{Pre-publication history}

The pre-publication history for this paper can be accessed here:

http://www.biomedcentral.com/1471-2296/5/12/prepub

\section{Publish with Biomed Central and every scientist can read your work free of charge}

"BioMed Central will be the most significant development for disseminating the results of biomedical research in our lifetime. "

Sir Paul Nurse, Cancer Research UK

Your research papers will be:

- available free of charge to the entire biomedical community

- peer reviewed and published immediately upon acceptance

- cited in PubMed and archived on PubMed Central

- yours - you keep the copyright

Submit your manuscript here:

http://www.biomedcentral.com/info/publishing_adv.asp 